\title{
Dosing Frequency of Inhaled Corticosteroids for Asthma Control: Is Once-Daily Administration Effective?
}

\author{
Jagdish P. Goyal ${ }^{1}$ (1) - Prawin Kumar ${ }^{1}$
}

Received: 2 November 2021 / Accepted: 5 November 2021/Published online: 17 November 2021

(c) Dr. K C Chaudhuri Foundation 2021

Inhaled corticosteroids (ICS) are the cornerstone for asthma treatment. The introduction of ICS in the late 1970s led to a significant shift in the clinical practice of asthma [1]. International guidelines, including the Global Initiative for Asthma (GINA), recommend ICS as the first line of asthma treatment. After the advent of ICS, the use of oral corticosteroids has dramatically reduced since it was associated with more side effects. Regular use of ICS has been shown to reduce asthma-related morbidity and mortality [2]. Several factors determine the effectiveness of ICS in asthma. These factors include plasma half-life, lipophilicity, dissolution rate, extent, and strength of receptor binding [3]. Furthermore, the type of device used by the patient also affects the ICS efficacy. In clinical practice, it has been noticed that poor compliance with asthma medication is the main reason for asthma exacerbation.

Dosing frequency of ICS is an essential aspect of asthma management, as it affects compliance to therapy and hence, overall effectiveness. Initially, it was used four-times daily dosing schedule, which was brought down to a twice-daily dosing schedule to improve compliance $[4,5]$. In addition, researchers have tried a once-daily dosing schedule for the management of asthma. It has been found that the simplicity of once-daily dosing improves compliance to therapy in patients with mild to moderate asthma [6].

In this issue of Indian Journal of Pediatrics, Goyal et al. [7] have presented an open-label, noninferiority randomized controlled trial on once-daily vs. twice-daily administration of inhaled budesonide in children (5-12 y) with mild or moderate well-controlled asthma. They randomly assigned the children to receive the equivalent inhaled budesonide in two groups, either once-a-day or divided into two similar dosages. The study shows that there was no significant

Jagdish P. Goyal

jpgoyal@rediffmail.com

1 Department of Pediatrics, AIIMS, Jodhpur, Rajasthan 342001, India median change in the diurnal variation in home peak expiratory flow rate (PEFR) and various clinic spirometric variables, i.e., PEFR, forced expiratory volume in one second $\left(\mathrm{FEV}_{1}\right)$, forced vital capacity $(\mathrm{FVC})$, and $\mathrm{FEV}_{1} / \mathrm{FVC}$ ratio over the 12 wk of follow-up between the two groups. The authors concluded that once-daily administration of inhaled budesonide is not inferior to twice-daily administration of an equivalent daily dosage of inhaled budesonide, and asthma control can be maintained with once-daily administration in most patients. This study offers important insight and adds to our knowledge of the dosing schedule of ICS. However, almost two-third of the children in this study had mild asthma, and the majority were well controlled in both groups. Current GINA guidelines also recommended step-down therapy as once-daily ICS in mild asthma [8]. Therefore, the clinical significance of this study seems to be questionable. Moreover, the authors failed to provide important information like adherence to ICS and adverse events in the studied participants. The monitoring of ACQ in less than 6 -y-old children also requires justification, since it is validated in children of more than $6 \mathrm{y}$ of age.

Despite some of the limitations of this clinical trial, the fact remains that this trial is probably one of the first of its kind from India. The findings of the current clinical trial emphasize clinicians to provide personalized asthma care with effective medication, which is convenient to use.

\section{Declarations}

Conflict of Interest None.

\section{References}

1. O’Byrne P, Fabbri LM, Pavord ID, Papi A, Petruzzelli S, Lange P. Asthma progression and mortality: the role of inhaled corticosteroids. Eur Respir J. 2019;54:1900491. 
2. Bårnes CB, Ulrik CS. Asthma and adherence to inhaled corticosteroids: current status and future perspectives. Respir Care. 2015;60:455-68.

3. Daley-Yates PT. Inhaled corticosteroids: potency, dose equivalence and therapeutic index. Br J Clin Pharmacol. 2015;80:372-80.

4. Toogood JH, Baskerville JC, Jennings B, Lefcoe NM, Johansson SA. Influence of dosing frequency and schedule on the response of chronic asthmatics to the aerosol steroid budesonide. J Allergy Clin Immunol. 1982;70:288-98.

5. Reed CE. Aerosol glucocorticoid treatment of asthma: adults. Am Rev Respir Dis. 1990;141:S82-8.

6. Kuna P, Creemers JP, Vondra V, et al. Once-daily dosing with budesonide/formoterol compared with twic-daily budesonide/formoterol and once-daily budesonide in adults with mild to moderate asthma. Respir Med. 2006;100:2151-9.
7. Goyal M, Guglani V, Kumar P, Randev S. Once-daily vs. twicedaily administration of inhaled budesonide for mild and moderate well-controlled childhood asthma: a randomized, controlled trial. Indian J Pediatr. 2021. https://doi.org/10.1007/ s12098-021-03753-1.

8. Global Initiative for Asthma. Global Strategy for Asthma Management and Prevention. 2021. Available at: https://ginasthma.org/ wp-content/uploads/2021/05/GINA-Main-Report-2021-V2-WMS. pdf . Accessed on 30th Oct 2021.

Publisher's Note Springer Nature remains neutral with regard to jurisdictional claims in published maps and institutional affiliations. 